\title{
Assessment of Women's Health Needs and Problems after Cesarean Section
}

Dr. Entesar Fatouh. Abd El-Moneim, Dr. Seham Shehata Ibrahim, Maha Adel Ali

Assist Prof. of Maternity and New born Health nursing, Faculty of Nursing- Helwan University, Lecturer of Maternity, Obstetrics and Gynecological Nursing, Faculty of Nursing

- Port Said University, B.Sc, Mansoura University

\begin{abstract}
Background: Cesarean Section is a form of childbirth in which a surgical incision is made through a mother's abdomen and uterus to deliver one or more babies.Aim: The aim of the current study was to assess health needs and problems of women after cesarean section.Subject and Methods: A descriptive research design was utilized in the current study. The study Setting was conducted at postpartum department at Mansoura city hospital. Subjects consisted of 200 posts Cesarean Section women were recruited to participate in this study. Tools; three tools were used for data collection and developed by investegator. A) First tool: a structed interviweing questionnair, B) second tool: assessment sheet of women's knowledge about selfcare after Cesarean Section, C) Third tool: assessment of women's health needs and health problems after Cesarean Section.Results: The results of the current study revealed that, the low level of knowledge among the studied women $(76.0 \%)$. The most common health needs among women were: awerence about family planning method (81.5\%) and need for family support (75.5\%). The common health problems among women were: lower abdominal pain (82.0\%), and sleep deficits (73.0\%).Conclusion: The study was concluced that there was a highly statistically significant relation between knowledge and reproductive tract problems and reproductive needs. In addition, between knowledge related to medical consultation and health needs. Recommendation: developing a health educational program concerning health needs and problems of women after Cesarean Section.
\end{abstract}

Key word: Cesarean Section, women, surgical incision, health needs, problems 


\section{INTRODUCTION}

A cesarean section is an operative delivery of the baby. It is the most common surgical procedure performed by obstetricians and is performed for many indications; it can be resorted to indications that solely benefit to the mother such as gestational diabetes, pre-eclampsia, failure to progress in labor, failed induction, and dystocia (Belfort et al., 2010). The Egyptian Demographic Health Survey in 2014 reported that, slightly more than half of the deliveries (51.8\%) in the five-year period before the survey were by caesarean section. The likelihood of a caesarean delivery increased with the advanced age of the mother and decreased with the child's birth order. Caesarean deliveries were more common in urban areas than in rural areas (ElZanaty, \& Way, 2014).

Cesarean section is safe, but it is still surgery, with risks and complications to be considered. The risks associated with cesarean delivery can be divided into those that are short term such as maternal death, hemorrhage, pain, emergency hysterectomy, wound infection, thrombosis, extended hospitalization, and incidental surgical injuries while, those that are long term risks such as adhesion formation, infertility or sub fertility, readmission to the hospital and risks of future pregnancies such as uterine rupture, abnormal placentation and hysterectomy (Shaban, 2007).

Women who had a cesarean section will have a range of immediate, short- and longer-term health needs. These will include general post-operative needs, such as wound care and pain relief, and specific postnatal needs such as support and advice relating to breast feeding, (Thomas and Paranjothy, 2001). The common postnatal educational topics include: Breast feeding, infant nutrition including vitamins, sleep patterns, rest, activity, exercises, weight gain, fever management, immunization schedule, family planning ,sexuality, medical check up, postpartum depression, anxiety, late postpartum hemorrhage, puerperal infection, nutrition and exercise (WHO, 2003) .

Nurse's role is crucial in assessing Women's Health Needs and Problems after Cesarean Section to help in prevention the complicatins. Nurses stays with the women 24 hours per day post Cesarean Section devlevery, which is why she should have essential knowledge and practice about nursing manegment during the pre and postoperative period of women undergoing cesarean section (Malani, 2005).

\section{Significance of the study:}

Women who delivered by cesarean birth have an additional care concern in the postpartum period, because they are not only postpartum patients, but post-surgical ones, as well as certain risks are higher after cesarean section than a vaginal delivery. The risk of maternal death from cesarean section is still three times greater than that with vaginal delivery. Postpartum bleeding is the most common cause of maternal mortality (Louise, 2007). 


\section{AIM OF STUDY:}

The aim of the present study is to assess health needs and problems of women post cesarean section.

\section{Research questions:}

- What are the health needs of women post cesarean section?

- What are the health problems of women post cesarean section?

\section{SUBJECT AND METHODS:}

\section{Technical Design:}

Research design: A descriptive research design was adopted in this study.

Setting: The study was conducted at the postpartum departments in Mansoura City Hospitals as follows; General Hospital, Eldawly Hospital, and Talkha Hospital.

Target Population: A convinent sample consisted of 200 women. The women were post cesarean section women attend to the previous mentioned hospitals during their hospital stay at the postpartum department hospitals. The criteria for subject inclusion were: a) Age ranged from 20-35 years, b) Free from medical diseases, c) Not more than three times CS.

Sampling technique: A convenient sample technique was followed for all post cesarean section women of chosen setting, depending on the selection criteria until the sample size was completed.

\section{Tools:}

Data were collected using the following three tools which were structured by researchers:

Tool (1): A structured interviewing questionnaire: it consists of four parts to collect the following data:-

-Part (1): The necessary socio demographic data.

-Part (2): Obstetrical history.

-Part (3): Menstrual and contraceptive history.

-Part (4): Knowledge Assessment Sheet: it was used to assess women's level of knowledge about self-care after caesarean section. It consists of nine parts as follows; medical consultation, early ambulation and exercise, rest, nutrition, wound care, perineal care, breastfeeding, breast care, sexual relation and family planning.

Scoring: For the knowledge items; a complete correct answer was scored 2, an incomplete correct answer was scored 1, and the incorrect answer was scored zero. For each area of knowledge, the scores of the items were summed-up and divided by the number of the items, giving a mean score for the part. The scores were converted into a percent score, and means and standard deviations were computed. Knowledge was considered high satisfactory level if the percent score was $(\geq 75.0 \%)$, moderate satisfactory level if the percent score was $(60.0-<75.0 \%)$, and low satisfactory level if it was less than $(60.0 \%)$. 
Tools (2): Women's Health Needs Assessment Sheet: it consists of three parts to collect the needed data among women about physical, psychological, and reproductive needs.

Tools (3): Health Problems Assessment Sheet: it consists of six parts as follow:

Cardiovascular, gastrointestinal, urinary, reproductive system problems; psychosocial problems.

\section{II- Administrative Design and Ethical Considerations:}

Before starting any step in the current study, an official letter was addressed from the dean of the Faculty of Nursing, Port-Said University to the directors of the identified study settings, requesting their cooperation and permission to include women in the study after explaining the purpose of the study. Purpose of the study was explained to each woman and a written consent was obtained. Those who agreed to participate were assured about confidentiality and privacy, and they have the right to withdraw from the study at any time without giving any reasons. This information was used for research purpose only.

\section{III-Operational design:}

Preparatory phase: The researcher reviewed the available local \& international related literature of current study. From using text books, articles, and scientific magazines, the tools for collection of data were prepared. The tools were reviewed by the supervisors, and panel of juries in the field of obstetric and gynecologic nursing, then, the needed modifications were done.

Content validity: It was ascertained by a Jury consisting of five experts in nursing fields, to make sure that the measuring instrument looks as what, it is measuring. Changes were done according to the experts opinions. This phase was carried out in a period of two weeks.

Testing reliability: Crombach alpha coefficient was calculated to assess the reliability of the developed tools through its internal consistency.

Pilot study: Pilot study was carried out on $10.0 \%$ (20 of the women) of the total sample. The purposes of the pilot study were to test the applicability and clarify the feasibility of the study tools and it served to estimate the time needed to complete the tools. It also helped to find out any obstacles and problems that might interfere with data collection, based on findings of the pilot study, certain modification of the tools were done. Subjects included in the pilot study were excluded from the study subjects. Following this pilot study, the process of data collection was performed. Modifications of some words in the tools were done according to the results of the pilot study.

The field work: The researcher identified herself for each participant, the purpose of the study was explained and a written consent was obtained. Collection of data covered a period of six months from the beginning of June, 2014 to the end of 
November; 2014.The researcher attained the study settings three days per week (one day for each hospital) from 9 am to $2 \mathrm{pm}$. At the post partum department women were interviewed individually during the second day after cesarean delivery during a period ranged from 20-30 minutes, the second day after delivery (before discharge from the hospital). The researcher obtained data about the women from their record sheet; the interview questionnaire sheet was filled in by the researcher. The researcher asked the women about their knowledge and self-care after cesarean section, and then, asked them about their problems and needs after cesarean section.

VI-Statistical Analysis: Data was collected, presented in tabular form. Percentages were calculated for qualitative data, mean and standard deviations were calculated for quantitative data using the Statistical Package for Social Sciences (SPSS) for statistical analysis. The Fisher's exact test, Qui square test, Kolmogorov - Smirnov test, and Monte Carlo test were used in this study to analysis the data.

\section{RESULTS:}

Table (1): shows the distribution of the studied women according to their socio demographic characteristics. This table indicates that, the age ranged between 20 and 35 years, with almost $(42.0 \%)$ are between 25 to 30 years of age. Seventy percent of the studied women are house wives. However, half of them (50.0\%) has secondary/technical school education. Almost all of them (98.5\%) sre married, and about two thirds (64.0\%) has a satisfactory monthly income

Table (2): illustrates the distribution of the studied women according to their health problems after cesarean section. In relation to cardiovascular problems, 40.5\% of women has hypotension. While, regarding gastrointestinal problems, more than half $(55.5 \%)$ of women has constipation. As regards urinary problems, 31.5\%of them has painful urination. Concerning reproductive tract problems, $82.0 \%$ of participants has lower abdominal pain. Regarding psychosocial problems, the majority of women (73.5\%) has sleep deficits.

Table (3): reveals the correlation between knowledge with the health problems and the needs after cesarean section among the studied women. As regards to health problems, it is noticed that, there is a statistically significant positive correlation between knowledge and reproductive tract problems after cesarean section $(r=0.176 \& p$-value $=0.013)$. Concerning the health needs, it is observed that, there is a statistically significant negative correlation between knowledge and reproductive needs after cesarean section among the studied women $(r=-0.169 \& p$-value $=0.024)$.

Figure (1): shows the mean scores of knowledge about self-care after cesarean section among the studied women. Women has a high mean score $(77.7 \%)$ about wound care. While, they has a moderate mean score $(55.6 \%)$ about sexual relation and family planning, but they has low mean score (49.9\%) about nutrition after CS among the studied women. 
Figure (2): shows the distribution of the studied women according to health needs after cesarean section. As regards physical needs, more than two thirds (74.0\%) of them has the need for wound care. Regarding psychological needs, nearly three quarters of women $(75.5 \%)$ has need for family support. However, concerning reproductive needs, the highest percentage of women $(81.5 \%)$ has the need for family planning method, and slightly more than two thirds of the studied women has the need to encourage early initiation of breastfeeding, breast care, and perineal care $(69.5 \%, 63.5 \%, \& 63.0 \%)$ respectively.

Table (1): Distribution of the studied women according to their socio demographic characteristics $(n=200)$.

\begin{tabular}{|l|l|l|}
\hline \multirow{2}{*}{ Socio demographic characteristics } & \multicolumn{2}{l|}{ Studied women } \\
& No. & \% \\
\hline Age (years) & \multicolumn{2}{l|}{} \\
\hline $20-<25$ & 77 & 38.5 \\
\hline $25-<30$ & 84 & 42.0 \\
\hline $30<35$ & 39 & 19.5 \\
\hline Level of education & \multicolumn{2}{l|}{} \\
\hline Illiterate & 24 & 12.0 \\
\hline Primary/ Preparatory school & 15 & 7.5 \\
\hline Secondary/Technical school & 100 & 50.0 \\
Graduate/Post graduate & 61 & 30.5 \\
\hline Occupation & \multicolumn{2}{|l|}{} \\
\hline Working & 60 & 30.0 \\
\hline House wife & 140 & 70.0 \\
\hline Marital status & \multicolumn{2}{|l|}{} \\
\hline Married & 197 & 98.5 \\
\hline Divorced & 3 & 1.5 \\
\hline Monthly family income & \multicolumn{2}{|l|}{} \\
\hline Satisfactory & 128 & 64.0 \\
Unsatisfactory & 72 & 36.0 \\
\hline
\end{tabular}


Table (2): Distribution of the studied women according to their health problems after cesarean section $(n=200)$.

\begin{tabular}{|c|c|c|c|c|}
\hline \multirow[b]{2}{*}{ Health problems after cesarean section } & \multicolumn{4}{|c|}{ Problems of studied women } \\
\hline & \multicolumn{2}{|c|}{ Present } & \multicolumn{2}{|c|}{ Absent } \\
\hline \multicolumn{5}{|l|}{ Cardiovascular problems } \\
\hline Hypertension & 19 & 9.5 & 181 & 90.5 \\
\hline Hypotension & 81 & 40.5 & 119 & 59.5 \\
\hline Hyperthermia & 40 & 20.0 & 160 & 80.0 \\
\hline Tachycardia & 44 & 22.0 & 156 & 78.0 \\
\hline Difficult breathing & 45 & 22.5 & 155 & 77.5 \\
\hline \multicolumn{5}{|l|}{ Gastrointestinal problems } \\
\hline Constipation & 111 & 55.5 & 89 & 44.5 \\
\hline Abdominal pain & 90 & 45.0 & 110 & 55.0 \\
\hline Vomiting & 24 & 12.0 & 176 & 88.0 \\
\hline \multicolumn{5}{|l|}{ Urinary system problems: } \\
\hline Painful urination & 63 & 31.5 & 137 & 68.5 \\
\hline Difficult in urination & 34 & 17.0 & 166 & 83.0 \\
\hline Bladder injury & 3 & 1.5 & 197 & 98.5 \\
\hline \multicolumn{5}{|l|}{ Reproductive tract problems } \\
\hline Hemorrhage & 13 & 6.5 & 187 & 93.5 \\
\hline Lower abdominal pain & 164 & 82.0 & 36 & 18.0 \\
\hline Hysterectomy & 2 & 1.0 & 198 & 99.0 \\
\hline Cracked nipple & 12 & 6.0 & 188 & 94.0 \\
\hline \multicolumn{5}{|l|}{ Psychosocial problems } \\
\hline Feeling of sadness & 48 & 24.0 & 152 & 76.0 \\
\hline Sleeping deficits & 147 & 73.5 & 53 & 26.5 \\
\hline Decline of social relations & 45 & 22.5 & 155 & 77.5 \\
\hline Change in recreation & 106 & 53.0 & 94 & 47.0 \\
\hline Feeling of isolation "loneliness" & 34 & 17.0 & 166 & 83.0 \\
\hline
\end{tabular}


Table (3): Correlation between knowledge with the health problems and the needs after cesarean section among the studied women $(n=200)$.

\begin{tabular}{|l|l|l|}
\hline \multirow{2}{*}{ Health problems and needs score after CS } & \multicolumn{2}{l|}{ Knowledge score } \\
\cline { 2 - 3 } Health problems after cesarean section & $R$ & p-value \\
\hline Cardiovascular problems & \multicolumn{2}{|l|}{} \\
\hline Gastrointestinal problems & -0.04 & 0.576 \\
\hline Urinary system problems & 0.086 & 0.227 \\
\hline Reproductive tract problem & 0.093 & 0.191 \\
\hline Psychosocial problems & $\mathbf{0 . 1 7 6}$ & $\mathbf{0 . 0 1 3}$ \\
\hline Composite Score & 0.044 & 0.533 \\
\hline Health needs after cesarean section & 0.121 & 0.087 \\
\hline Physical needs & & \\
\hline Psychological needs & 0.015 & 0.831 \\
\hline Reproductive needs & 0.043 & 0.545 \\
\hline Composite Score & $\mathbf{- 0 . 1 6 9}$ & $\mathbf{0 . 0 2 4}$ \\
\hline
\end{tabular}

$r$ : Spearman Rho correlation coefficient $\quad *$ significant at $p \leq 0.05$

Figure (1):

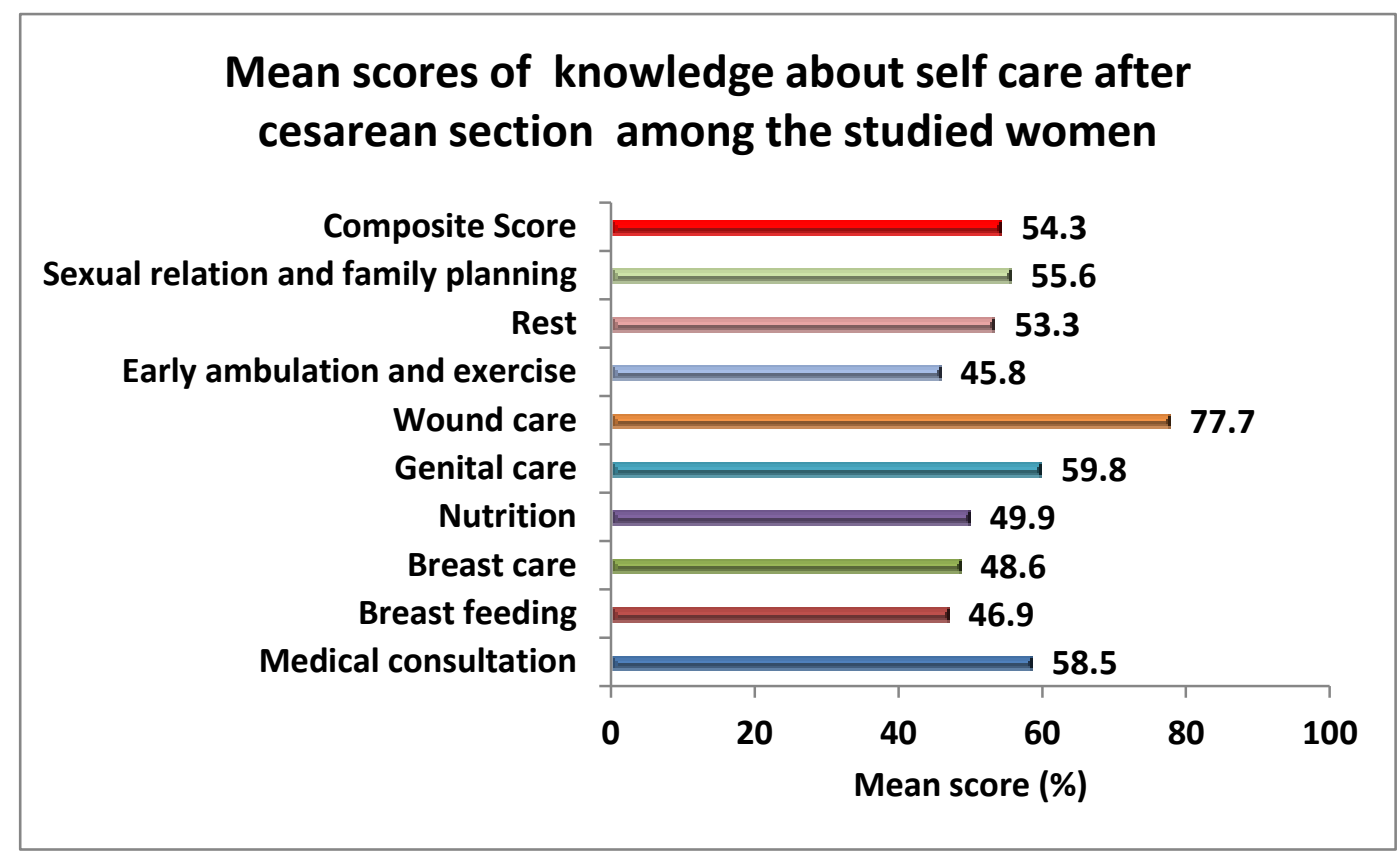


Figure (2):

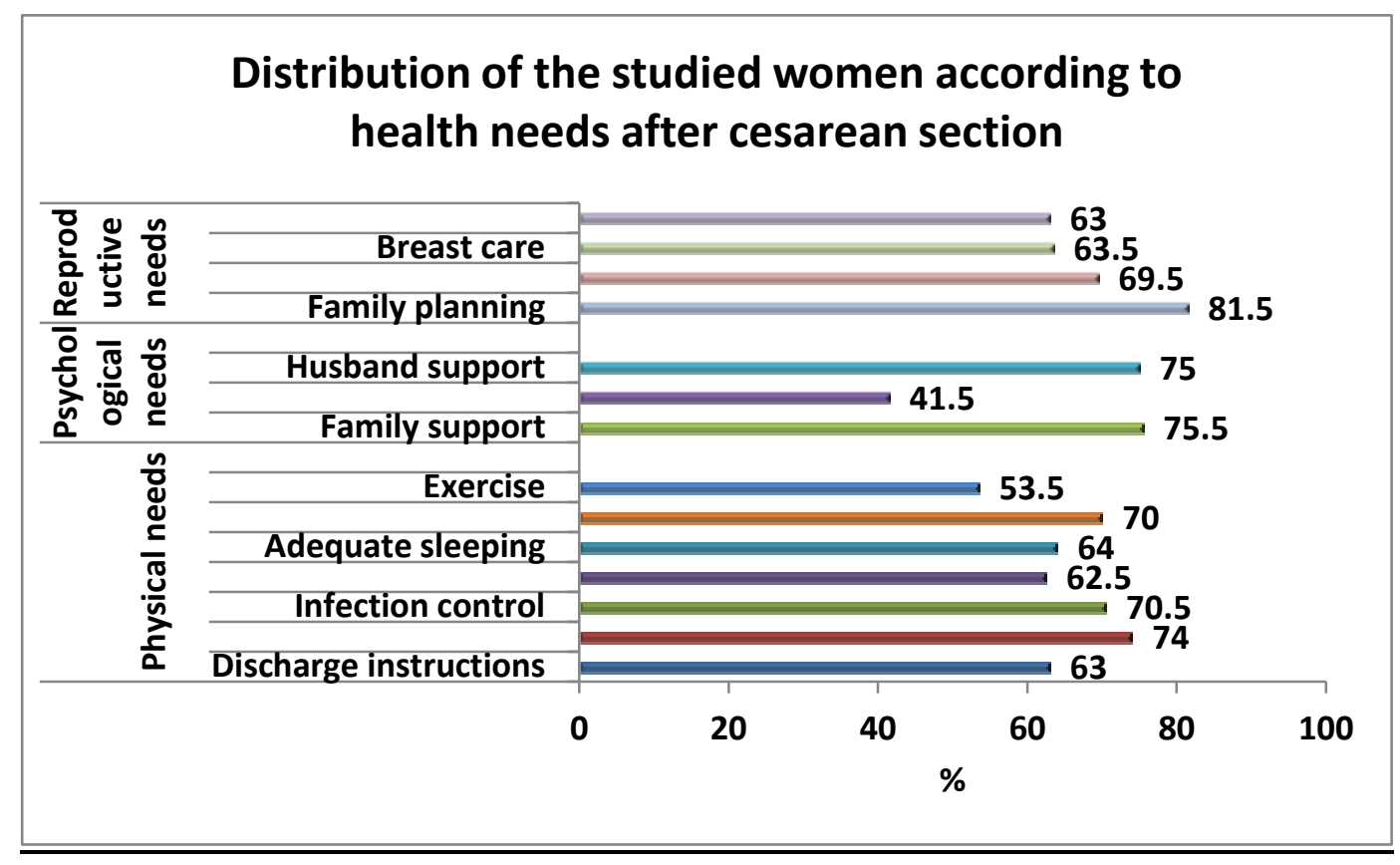

\section{DISCUSSION:}

Cesarean section is a major abdominal surgery; it can be life saving for both mother and baby in a small number of cases. It is a surgical procedure that might carries more risks to both the mother and the baby more than vaginal labor (Annana, 2005).High CS rates have become a public health concern throughout the world. Women are almost three times more likely to have a cesarean birth now than they were twenty years ago. According to the World Health Organization (2009), no country in the world is justified in having a cesarean rate greater than $15.0 \%$.

This study aims to assess the health needs and the problems of women after cesarean section. As yielded by the present study, the mean score of knowledge about self-care was (54.3 \pm 8.9$)$; the maximum possible score was 100, the majority of women had low level of knowledge (76.0\%) compared to $23.0 \%$ had moderate level, and $1.0 \%$ had a high level. It may be due to lack of awareness programs for women during their reproductive period.

These findings were congruent with Burt (2005) who studied the women's perception of post cesarean problem, they mentioned that, knowledge and attitudes of women about caesarean section delivery were overall, $63.5 \%$ of women scored weak on knowledge question. In addition, Rajan and Nayak (2014) found that, the mean knowledge score was (14.98) whereas maximum possible score was (30).

The current study findings were in contrast with Rajan and Nayak (2014) who reported that, $60.0 \%$ of women had an average level of knowledge, but in the current study, $23.0 \%$ of women had a moderate level of knowledge. From the point of view of the researcher, it may be due to lack of awareness, health educational programs, and 
discharge instructions for women about caring after cesarean section and warning signs in our communities. In addition, Darling and Bazil (2014) noticed that,46.0\% of postnatal mothers had an adequate knowledge, $47.0 \%$ had a moderately adequate knowledge, and $7.0 \%$ of postnatal mothers had an inadequate knowledge regarding self-care after childbirth. Moreover, Ghotbi et al., (2014) found that, mothers' knowledge scores were poor, intermediate, and good among cases $(55.6 \%, 37.9 \%$, \& $6.5 \%$ ) respectively.

As regards women's health needs after cesarean section, the present study findings illustrated that, $63.0 \%$ of women had a need for discharge instructions. As well, Satra (2013) stated that, the discharge instruction is very important to mother after cesarean section to take care of herself and to predict any complication; the mother needs instructions about incision care, activity, and warning signs.

The current study findings showed that, the mothers' health needs were wound care (74.0\%), infection control (70.5\%), nutrition (62.5\%), adequate sleeping (64.0\%), pain relieve (70.0\%), and exercise (53.5\%). These results were supported by Joy et al. (2014). From the researcher point of view, the previous mentioned needs are very important for women to enhance wound healing and to restore their health and strength.

The current study findings go on the same line with $C D C$ (2001)in its guideline preventing surgical site infection, which was recommended educating mothers and their families on wound care, including symptoms of infection and the need to report such symptoms. Karlstrom, Engstom, and Norbergh (2007) who mention that, it is important to teach the mother in post cesarean period the proper breastfeeding, breast care, and perineal care techniques. It is also supported by Bick (2004) who studied the postnatal health needs of women post cesarean section in England, and stated that, women who had a CS will have a range of immediate, short, and long term health needs. These will include general post-operative needs, such as wound care, pain relief, and specific postnatal needs, such as support and advice related to breastfeeding.

As yielded by the present study, 53.5\% of women need to exercise after cesarean section. This was in the same line with the findings, which observed by Masood, Siddiqui, Masood, and Mumtaz (2011), they found that, $57.0 \%$ of respondents said that, early maternal ambulation after an uncomplicated CS can help in early recovery. From the point of view of the researcher, physical exercise helps women to restore their body function, strengthen muscles especially pelvic floor and abdominal muscles; this help women in early recovery to be able to perform their daily activities.

As observed by the present study findings, two thirds of women $(62.5 \%)$ need for nutritional support. This result was supported by Corleone (2013) who stated that, the best way for women to ensure adequate healing following a caesarean section is to eat a healthy diet. Also, Murphy, and Fullerton(2005) who had emphasized that, certified nurse midwives must be knowledgeable about the risks for mother and 
newborn baby, screen appropriately women underwent CS, and be able to counsel them with regard potential adverse outcomes.

According to psychological and reproductive needs, the majority of the studied women reported that, they need family support, husband support, and family planning. From the point of view of the researcher, psychological support is important during postpartum period to eliminate occurrence of depression. World Health Organization (WHO) (2009) pointed out that, postpartum care must be a collaboration between parents, families, caregivers trained or traditional, health professionals, health planners, health care administrators, other related sectors, community groups, policy makers and politicians.

The current study findings showed that, $69.5 \%$ of women had needed for encourages early breastfeeding; it may be due to increase mother-child bonding, and relieve pain. With respect, Masood et al. (2011) found that, 31.3\% of their study participants were in favour of early initiation of maternal feeding 2-4 hours. Also, Gists (2002) noticed that, the entire study group who started early feeding had an early return of bowel function as evidenced by early passage of flatus and bowel movement.

In relation to women's health problems after cesarean section, the current study findings showed that, $40.5 \%$ of women had hypotension after caesarean section; from the point of view of the researcher, it may be a side effect of spinal anaesthesia and blood loss. This result is in agreement with Ayala (2009) who studied maternal hypotension after cesarean section. He found that, about one quarter of deliveries by cesarean section had the risk of decrease blood pressure after cesarean section. On the other hand, Mitra (2010) observed that, the incidence of hypotension can be as high as $80.0 \%$ especially after spinal anaesthesia. In addition, Mercier, Augè, Hoffmann, Fischer, and Le Gouez (2013) stated that, the incidence of hypotension can be as high as $70.0-80.0 \%$ when pharmacological prophylaxis is not used.

The current study findings were in accordance with Krucik (2012) who stated that, women after cesarean section were at risk for tachycardia, and difficulty breathing, $22.0 \% \& 22.5 \%$ of women under the current study complain from tachycardia, and difficult breathing respectively. This result also is similar to Barret (2009) who studied the major concerns of women after caesarean section delivery. He found that, about one quarter of women suffered from tachycardia after cesarean section; this is may be due to hypotension and low fluid intake.

It was observed that, women after caesarean section had some gastrointestinal problems such as constipation (55.5\%), abdominal pain (45.0\%), and vomiting $(12.0 \%)$. This may be an action for spinal anaesthesia, and abdominal manipulation during operation. These findings were supported by Adeli, Razmjoo, Tara, and Ebrahimzade (2013) who concluded that, gastrointestinal complications are the main complication in patients after caesarean section.

As regards constipation, the result of the study clarified that, 55.5\% of women complained from constipation. This result is due to lack of fluids and food intake and 
lack or absence of exercise. This is in agreement with Diamond(2000) who found that, half of the women were reporting complain of constipation and used laxative to reduce postpartum constipation. Centers for Disease and Control Prevention (CDC) (2004) pointed out that, many patients experienced constipation from lack of fluids and food intake, bowel tone is sluggish as a result of the elevated progesterone level. Teoh, Shah, and Mah (2007) stated that, one of the general postoperative complications is gastrointestinal problems, which are the most important problems after cesarean section leading to mother's dissatisfaction and prolong hospitalization.

The current study findings showed that, women after caesarean section were at risk for urinary system problems such as painful urination (31.5\%), difficult in urination(17.0\%), and bladder injury (1.5\%). These findings were emphasized by Yoshida, Ishii, Saito, and Azuma (2012) who stated that, postpartum urinary disturbance is a relatively common complication.

The current study findings revealed that, $82.0 \%$ of women had a lower abdominal pain. In this respect, William (2005) emphasized the importance of investigating the various factors associated with pain, which are mainly; medical, technical and psychological factors. Similarly, Gilbert (2007) examined the postoperative pain after CS and found that, postoperative pain is usually underestimated, although it could be easily alleviated by pain relief measures.

The current study finding revealed that, $6.5 \%$ of women had hemorrhage. This finding go on the same line with Belfort, Lockwood, Levine, and Barss (2015)who estimated that, from 1 to 5 percent of deliveries developed a postpartum hemorrhage. Also, Robertson (2011) confirmed the association between the condition of the uterus during the postoperative period and the incidence of postpartum hemorrhage and puerperal infection.

As observed by the present study findings, women may develop psychosocial problems after CS such as feelings of sadness (24.0\%), sleeping deficits (73.5\%), the decline of social relations (22.5\%), change in recreation(53.0\%), and feeling of isolation "loneliness" (17.0\%). These results were supported by Verdult (2009), these problems may be due to inadequate nutrition, rest, and relaxation as a result of hospitalization, it may be also due to new life, fear of dealing with the baby or hormonal effect.

The current study findings showed that, there was a high statistically significant relationship between knowledge and reproductive needs after cesarean section among the studied women (pvalue $\leq 0.05$ ). This result is in the same line with Rinehart (2001) who pointed out that, women after cesarean section have special needs and concerns of social, psychological and clinical nature. The skillful midwife uses all of her talents-intellectual, interpersonal communication, intuition and judgment-to protect and to empower the post caesarean women in her care. The technical information about caesarean sections used to educate parents, to develop practice and to heighten awareness in the women and parents. 
As yielded by the present study, there was a high statistically significant relationship between knowledge and reproductive tract problems after cesarean section among the studied women $(p$-value $\leq 0.05)$. From the point of view of the researcher, increased level of knowledge helps women to take precautions to prevent complications.

These results are emphasized by William (2006) who studied the postpartum health state relative to cesarean section delivery in U.S and explored the current state of knowledge on postpartum health in caesarean section delivery and highlighted that, to maximize postpartum health; providers of obstetric care in clinicians must initiate the discussion about postpartum health during antenatal visits and encourage women to enlist needed support early in the postpartum period

\section{CONCLUSION:}

The results of the present study demonstrestes that, there was a statistically significant positive correlation between level of knowledge and reproductive tract problems. In addition, there was a statistically significant negative correlation between level of knowledge and reproductive needs after cesarean section among the studied women.

\section{RECOMMENDATIONS:}

Based on the findengs of the present study, the following ae recommended:

- Raise women's awerness about knowledge and practice toward self-care after cesarean section.

- Simplified educational booklets with pictures for non-educated women about cesarean section self-care should be available in different health settings to provide them the necessary information and practice.

- Antenatal clinic and services in primary care should develop educational programs on post cesarean section health needs and problems regarding (breast-feeding, breast care, wound care, perineal care, and exercises).

- Further studies about long-term maternal morbidities associated with cesarean section are needed.

\section{REFERENCES:}

Adeli, M., Razmjoo, N., Tara, F., \& Ebrahimzade, S. (2013): Effect of early post cesarean feeding on gastrointestinal complications. Nurs Midwifery Stud; 1(4):176-81. DOI: $10.5812 / \mathrm{nms} .10184$.

Annana', H. (2005): Caesarean Section Past/ Recent/ Future. MISC Journal of Medical Islamic Students' Committee. 2:18-19.Available From the Net: http://www.islamicblock.org.

Ayala, M. (2009): Maternal hypotension after cesarean section. Department of Public Health, Washington; (Online). Retrieved from: www.healthline. Com. 
Barret, N. (2009): Major concerns of women after cesarean section delivery. Royal College Obstetricians and Gynecologists. J Obstetric Gynecologic Neonatal Nurse; 23(1): 53-9. Retrieved from: www. Cog.org.uk.

Belfort, M., Clark, S., Saade, G., Kleja, K., Dildy, G., Van Veen, T.R., Akhigbe, E., Frye, D.R., Meyers, J.A., Kofford, S. (2010): Hospital readmission after delivery: evidence for an increased incidence of non-urogenital infection in the immediate postpartum period. American Journal of Obstetrics and Gynecology; 202(1): 35e1$35 \mathrm{e} 7$.

Belfort, M.A., Lockwood, C.J., Levine, D., \& Barss, V.A. (2015): Overview of postpartum hemorrhage .Up To Date .Available at: http://www .up to date. com/contents/overview-of-post partum hemorrhage.

Bick, D. (2004): The postnatal health needs of women following caesarean section, Royal College of Nursing, Thames Valley University; p.p: 1-11.

Burt, A.S. (2005): Women perception of post cesarean problem, cesarean section. International Journal of Nursing Studies; 26(5): 1118-1127. best. Obstetrics and gynecology Management; 36(2): 98-108.

Centers for Disease and Control Prevention (CDC), (2001): Infection Associated with Cesarean Section, Hospital Infection Programmes, website, www.cdc.gov.; Accessed: $4^{\text {th }}$ of March, 20008.

Centers for Disease and Control Prevention (CDC), (2004): Post cesarean section surgical site infection. Retrieved from: www.cdc.gov.

El-Zanaty, F., \& Way, A.A. (2014): Egypt Demographic and Health Survey 2014. Cairo, Egypt: Ministry of Health, El-Zanaty and Associates, and Macro International.

Corleone, J. (2013): Diet tips for mothers after cesarean delivery. Available at: http://www.livestrong.com/article/221971-diet-tips-for-mothers-after-cesareandelivery

Darling, B., \& Bazil, A.B. (2014): Knowledge and attitude of postnatal mothers regarding self-care after childbirth in selected maternity centers in Madurai. Journal of Science; 4(1): 40-44

Diamond, A. S. (2000): Post Partum, Post Cesarean Section Complication, Can J Public Health , May-Jun; 99(3):206-11.; Accessed: 16th of May, 2009. 
Ghotbi, F., Sene, A., Azargashb, E., Shiva, F., Mohtadi, M., Zadehmodares, S., Farzaneh, F., \& Yasai, F. (2014): Women's knowledge and attitude towards mode of delivery and frequency of cesarean section on mother's request in six public and private hospitals in Tehran, Iran. Journal of Obstetrics and Gynecology Research; doi:10.1111/jog.12335.

Gilbert J. (2007): Indications for cesarean section. Uptodate. Available at: Http://Www.Uptodate.Com.

Joy, S., Contag, S.A., Talavera, F., Carter, J.S., Isaacs, C., \& Pritzker, J.G. (2014): Cesarean delivery. Medscape. Available at: http:// emedicine. medscape.com/article/263424-overview\#a4

Karlstrom, A., Engstom, R., \& Norbergh, K. (2007): Postoperative pain ceasarean birth affects breastfeeding and infant care. Journal of obstetrics gynecolocal neonatal nursing; 36(5): 430-40.

Krucik, G. (2012): Cesarean section complications. Health line. Available at: http://www.healthline.com/health/pregnancy/complications-cesareansection\#Overview1.evaluation. Birth; 40: 125-133.

Louise, H. (2007): Fear a factor in surgical births. Retrieved from: http://www.smh.com.au/news/national/fear-a-factor-in-surgicalbirths/2007/10/06/1191091421081.html.

Maloni J. and Park S. (2005): Post Partum Symptoms after Ante Partum Bed Rest. Journal of Obstetric, Gynecological and Neonatal Nursing: 34 (2). P.p. 163-171.

Masood, S.N., Siddiqui, I.A., Masood, M.F., Masood, Y., \& Mumtaz, S.N. (2011): To assess the practices about initiation of oral maternal feeding after cesarean section under regional anesthesia. Pak J Med Sci; 27(5): 996-1000.

Mercier, F.J., Augè, M., Hoffmann, C., Fischer, C., \& Le Gouez, A. (2013): Maternal hypotension during spinal anesthesia for caesarean delivery. Minerva Anestesiol; 79: 62-73.

Mitra, J.K. (2010): Prevention of hypotension following spinal anesthesia in caesarean section - then and now. Kathmandu Univ Med J; 8(32): 415-419.

Murphy, Deirder, Libeling, R., Verity, L., Swingler, R., \& Roshni (2005): Early maternal and neonatal morbidity associated with operative delivery in second stage of labor: a cohort study. The Lancet; 385(October 13): 1203. An E 07.

Rajan, E., \& Nayak, S. (2014): Effectiveness of self-instructional module on knowledge of post-operative self-care for mothers undergoing elective caesarean 
section in selected hospitals, Mangalore. Nitte University Journal of Health Science; 4(4): 39-41.

Rinehart, H.M.D. (2001): Cesarean section delivery. Technical issues for midwives. Retrieved from: www. StorkNetFamily.com.

Robertson, A. (2011): Post-cesarean wound infection, Department of Obstetrics and Gynecology, Brigham and Women's Hospital, Boston, MA., Health line Pregnancy Guide, Health Article.

Satra, L. (2013): Discharge instructions for cesarean section (C-Section). Honor Health. Available at: https://www .honor health .com/ sites/ default/ files/ documents/medicalservices/discharge-instructions-for-cesarean-section.pdf

Teoh, W.H, Shah, M.K, \& Mah, C.L. (2007): A randomized controlled trial on beneficial effects of early feeding post-caesarean delivery under regional anesthesia. Singapore Med J; 48(2): 152-7.

Thomas, J., \& Paranjothy, S. (2001): National sentinel cesarean section audit. Royal college of Obstetricians and Gynecologists, Clinical Effectiveness Support Unit, London.

Verdult, R. (2009): Psychological aspects in adults. Journal of Prenatal and Perinatal Psychology and Medicine; 21(1/2): 17-28.

Williams, D. (2005): The top 10 reasons elective cesarean section should be on the decline. AWHONN Lifelines; 9(1): 23 - 24.

William, M. (2006): Postpartum health relative to cesarean section delivery. J Midwifery Women's Health.US; p.p: 242-8.

World Health Organization (WHO), (2003): Pregnancy, childbirth, postpartum and newborn care: a guide for essential practice. Retrieved from: Www.who.int/ reproductive health.

World Health Organization, (2009): Monitoring emergency obstetric care: a handbook. UNFPA, UNICEF and AMDD. Geneva.

Yoshida, A., Ishii, K., Saito, K., \& Azuma, I. (2012): A case of acute urinary retention after cesarean section caused by herpes zoster infection.Open Journal of Obstetrics and Gynecology; 2: 202-205. 


\section{تقيبيم الاحتياجات والمشاكل الصحية للسيدات بعد الولادة القيصرية}

مها عادل على محمود، أ.م. د/انتصار فتوح عبد المنعم ، د/سهام شحاتة إبراهيم

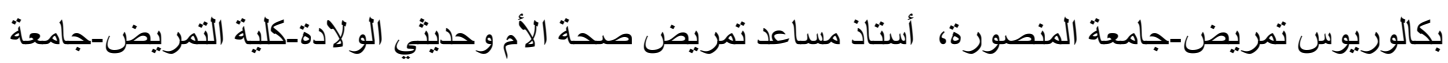
حلوان، مدرس تمريض الأمومة و النساء و التوليد- كلية التمريض- جامعة بورسعيد

\section{الخلاصة}

الو لادة القيصرية عبارة عن شق جراحي في بطن ورحم الأم لو لادة طفل أو أكثر. و وهى عادة تجرى عندما تمثل الو لادة الطبيعية خطر على حياة الأم والجنين. تهدف هذه الدراسة الوصفية إلى تقييم الاحتياجات و المشاكل

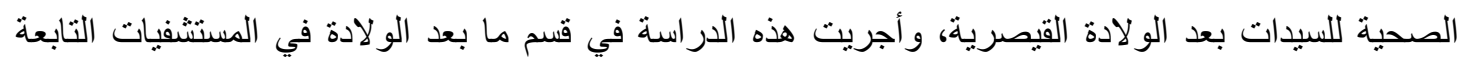

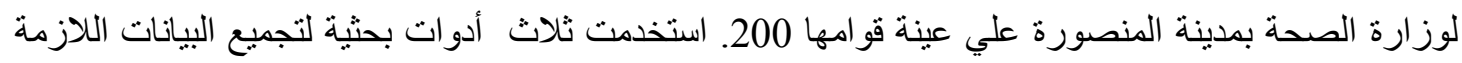
للار اسة: استمارة مقابلة شخصية، استبيان لتقييم معلومات السيدات عن الرعاية الذاتية بعد الولادة القيصرية،

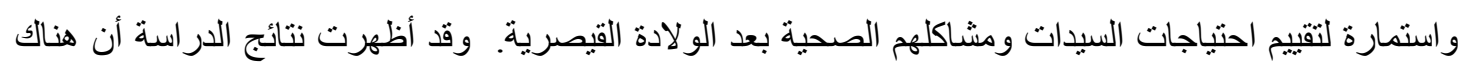
نقص في معلومات السيدات عن الرعاية الذاتية بعد الولادة القيصرية وأن حوالي (81.5\%) يحتاجون معلومات بودة عن تنظيم الأسرة و(75.5\%) يحتاجون مساندة من العائلة، وأن (82\%) يعانون من آلام أسفل البطن وأن

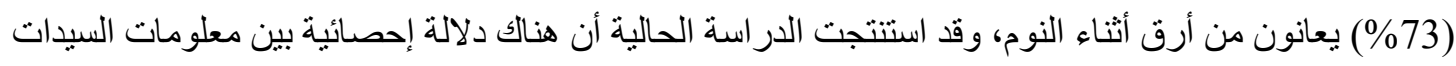
عن الرعاية الذاتية و المشاكل التناسلية و أيضا بين معلومات السيدات والاحتياجات التناسلية بعد الو لادة القيصرية، وكذلك هناك دلالة إحصائية بين معلومات السيدات عن الكثف الطبي واحتباجات السيدات بعد الو لادة القيصرية.

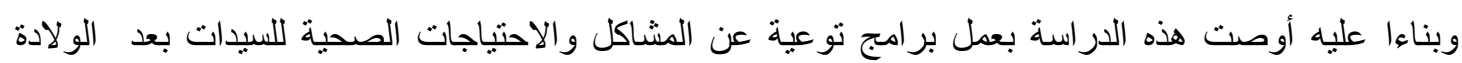

